\title{
Design of Complementary Hexagonal Metamaterial Based HMSIW Band-Pass Filter and Reconfigurable SIW Filter Using PIN Diodes
}

\author{
Hichem Boubakar ${ }^{1}$, Mehadji Abri ${ }^{2}$, and Mohamed Benaissa ${ }^{1,3}$ \\ ${ }^{1}$ Information Processing and Telecommunications Laboratory (LTIT), Faculty of Technology, University of Bechar, Algeria. \\ ${ }^{2}$ STIC Laboratory, Faculty of Technology, University of Tlemcen, Algeria. \\ ${ }^{3}$ Electrical Engineering Department, Abou Bekr Belkaid University of Tlemcen, PO BOX 119,13000, Tlemcen, Algeria \\ Corresponding author: Hichem Boubakar (e-mail: hichemriky@gmail.com).
}

\begin{abstract}
This paper is divided into two sections, in the first section, a new SIW and half-mode SIW band-pass filters based on complementary hexagonal metamaterial cells (C-HMCs) are proposed. Firstly, the SIW is analyzed in the case of using two C-HMC cells and in the case of using four of these cells. Secondly, the HMSIW tunable BPF is studied and optimized. The size of the half mode is reduced by almost $50 \%$. This filter design has a very low insertion loss, and significant transmission bandwidth extending from $5.9 \mathrm{GHz}$ to $6.5 \mathrm{GHz}$. In the second section of this paper, an electronically reconfigurable SIW band-pass filter is proposed. By implementing two PIN diodes in the gaps of the two C-HMC, the result of turning the diodes ON or OFF individually is switching in the frequency center, between $5.8 \mathrm{GHz}$ and $6.8 \mathrm{GHz}$. Also, a dual-band with two frequency centers at $5.6 \mathrm{GHz}$ and $7.4 \mathrm{GHz}$ is achieved by turning both of the diodes ON. In addition, the metamaterial properties of all the proposed filters are investigated and presented in this work.
\end{abstract}

INDEX TERMS Band-pass filter, C-HMC, C-SRR, metamaterials, PIN diodes, reconfigurability.

\section{INTRODUCTION}

D UE to the development of modern radio frequency and microwave systems these days, there are new devices that are much more miniaturized, multifunctional, and can work with multiple bands. For the reason of their major role in those systems, filters are gaining more and more attention especially electronically reconfigurable ones.

Microstrip has been the first based choice structure for the famous tunable bandpass filters (BPF). But with this choice, some disadvantages like narrow tuning range and a high loss are present $[1,2]$. Meanwhile, substrate integrated waveguide (SIW) grows to be the best alternative to implement microwave filters. Because of the low loss, the less complexity, along with other qualities that make SIW a very suitable choice, such as high-quality factor, easy integration, low cost, high power handling, and the ability of mass production [3-5].

Overall, we can say that it has the merits of both microstrip and traditional metal waveguides. The design of basic SIW structures involves two metallic layers one on the top and the other on the bottom, separated by a dielectric, and connected by metallic vias on the sidewalls, which realize a rectangular waveguide transmission line [6].
In order to further improve the compatibility of filters in general with the rapidly develop modern wireless communication systems that are going more and more miniature, a half mode substrate integrated waveguide (HMSIW) is proposed. As a structure that has the same characteristics of a SIW but with half of its size. This means more miniaturization, resulting in better integration with other circuits.

Researchers have used multiple methods to obtain reconfigurability, such as diodes [7-10], or electrostatic MEMS [11,12]. In addition, several metamaterials-based filter structures are proposed in order to change their characteristics [13]. And adding reconfigurability to the metamaterial in $[14,15]$.

This article proposes new bandpass filter structures. These structures are even more miniaturized compared to previous researches because of the loaded complementary-Hexagonal Metamaterial cells on the SIW or HMSIW filter. The simulation results of each design have different passing bandwidths with different properties to fulfill multiple needs in the telecommunication field. Furthermore, an original electronically reconfigurable filter using the same resonators is investigated. Two PIN diodes are used to switch between three different cases, where these diodes are implemented in 
a less complicated and an effected method compared to previous studies.

This paper is organized as follows:

several original band-pass filters are proposed, starting with a simple SIW BPF loaded with 2 C-HMC, and another one with 4 C-HMC. Secondly, a HMSIW filter with $2 \mathrm{C}-\mathrm{HMC}$ is studied. Finally, a reconfigurable tunable SIW filter based on complementary hexagonal shape metamaterial resonators and PIN diodes is proposed. The center frequency of this filter can be changed electronically by turning the diodes $\mathrm{ON}$ and OFF, which also can change its state between a single or a dual-band filter.

\section{THEORY OF SIW AND METAMATERIAL C-HMC}

\section{A. COMPLEMENTARY-HEXAGONAL SHAPE METAMATERIAL}

Metamaterial based complementary split-ring resonators (CSRR) comprise mutually coupled open-loop resonators, engraved on a metallic surface. one ring is in the inside of the other, separated by a determent gap, while the openings of these loops are on the opposite side of each other, as shown in fig.1. The edge capacitance effect between these rings is making the C-SRR resonate. The transmission characteristic of the transmission line will change, following the change in the electric field caused by printing the defect pattern or the rings on the ground plane, also known as defected ground structure (DGS) [16]. Having the same characteristic as SRRs, C-SRR does create a stopband that can stop the electromagnetic waves effectively from passing through. Filters based on microstrip C-SRRs are normally carved in the middle of the transmission band or the defect geometry, which will sustain the size of the circuit along with excited by the electric field of the microstrip. Therefore, C-SRR is more suitable to be loaded into SIW or HMSIW for the development of the microstrip device and miniaturization [17].

In the first section of this work, a C-HMC shape is being used, which is a simple structure of C-HSSR that is hexagon shape metamaterial used by [18] and [19]. The C-HMC consists of one ring and two arms sticking and pointing to the inside of the cell. Those modifications are made to increase the electric length, and as a result, we have more miniaturization.

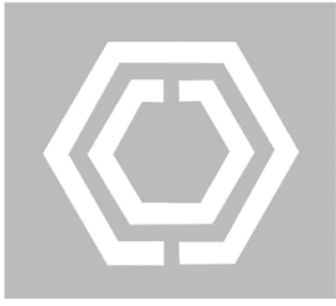

(a)

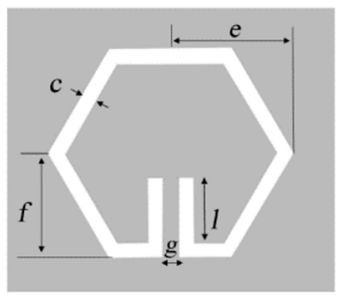

(b)
FIGURE 1. Diagrammatic sketch of (a) C-HSRR and (b) C-HMC

\section{B. SUBSTRATE INTEGRATED WAVEGUIDE}

In the literature, the SIW guide is a dielectric substrate with two metallic conductive layers. One layer on the top and the other on the bottom of the substrate, connected with a line of periodically set vias on the sidewalls, as revealed in fig.2. Where $d$ is the diameter of the metallic via holes and $p$ is the periodical distance between two consecutive vias. By consider ad being the waveguide dimension in dielectricfilled waveguide $[5,20]$, and $f_{c}$ to be the cut-off frequency of the fundamental mode $\mathrm{TE}_{10}$. The following equations can be written:

$$
\begin{aligned}
a & =\frac{a d}{\sqrt{\varepsilon_{r}}} \\
f_{c} & =\frac{c}{2 a d}
\end{aligned}
$$

And the width of the SIW can be calculated using equation (3):

$$
a=a s-\frac{d^{2}}{0.95 p}
$$

Two conditions are meant to be respected, in order to avoid the radiation and return loss that can be caused due to field leakage from the gaps between vias: $p \leq 2 d$ and $d<\frac{\lambda_{g}}{5}$ where $\lambda_{g}$ is the guided wavelength defined by [21]:

$$
\lambda_{g}=\frac{\pi}{\sqrt{\frac{(2 \pi f)^{2} \varepsilon_{r}}{c^{2}}}-\left(\frac{\pi}{a}\right)^{2}}
$$

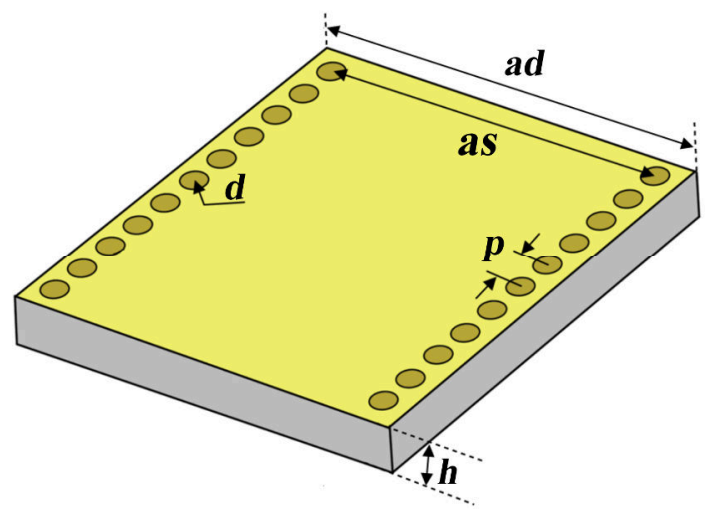

FIGURE 2. Diagrammatic sketch of SIW.

\section{THE EFFECTIVE REFRACTIVE INDEX EXTRACTION}

The method used to extract the effective refractive index $(n)$ is Nicolson-Ross-Weir (NRW) and can be calculated [22,23]. The complex simulated results coefficients $S_{21}$ (transmission) and $S_{11}$ (reflection) of the design are applied as based for this method. This process was first introduced to apply to metamaterials by Smith et al [24]. If the incident wavelength is wider than the basic components of the complex medium it is possible to determent the sign of the refractive index using NRW equations. Those equations are calculated by reversing the next formulas, where $k$ and $d$ are the wave number and the thickness of the simulated layer, respectively, and $\mathrm{t}^{\prime}=S_{21}$ 
(transmission) and $r^{\prime}=S_{11}$ (reflection) simulated coefficients [24].

$$
\begin{aligned}
& \operatorname{Re}(n)= \pm \operatorname{Re}\left\{\frac{\arccos \left[\frac{1}{2 t^{\prime}}\left(1-{r^{\prime}}^{2}+{t^{\prime}}^{2}\right)\right]}{k d}\right\} \\
& \operatorname{Im}(n)= \pm \operatorname{Im}\left\{\frac{\arccos \left[\frac{1}{2 t^{\prime}}\left(1-{r^{\prime}}^{2}+t^{\prime 2}\right)\right]}{k d}\right\}
\end{aligned}
$$

\section{SIW AND HMSIW LOADED WITH C-HMC}

\section{A. SIW BPF LOADED WITH 2 C-HMC}

The SIW filter designed in this part set to function within the C- band, and loaded with two C-HMC. Rogers 5880 is used as a substrate, which has a relative permittivity of 2.2 , and loss tangent 0.0009 , and thickness of $\mathrm{h}=0.508 \mathrm{~mm}$. The thickness of the conductors set to be $0.05 \mathrm{~mm}$, and with an effective size of about $8 \mathrm{~mm} \times 14.48 \mathrm{~mm}$ (fig.3). This filter is considered to be positively small. All dimensions of this structure are organized in Table I.

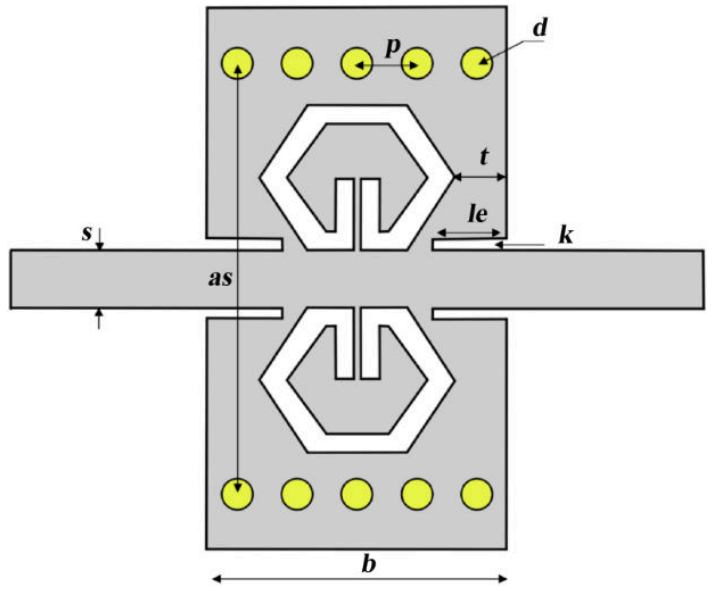

FIGURE 3. Layout of the tunable SIW filter with a two C-HMC.

TABLE I. Dimensions of the SIW proposed tunable filter with two C-HMCs (unit: $\mathrm{mm}$ ).

\begin{tabular}{cc|cc}
\hline \hline Parameters & Dimensions & Parameters & Dimensions \\
\hline as & 11.52 & $k$ & 0.3 \\
$d$ & 0.8 & $e$ & 2.63 \\
$p$ & 1.6 & $f$ & 1.95 \\
$b$ & 8 & $c$ & 0.5 \\
$s$ & 1.53 & $g$ & 0.2 \\
$h$ & 0.508 & $l$ & 1.9 \\
$l e$ & 2 & $t$ & 1.37 \\
\hline \hline
\end{tabular}

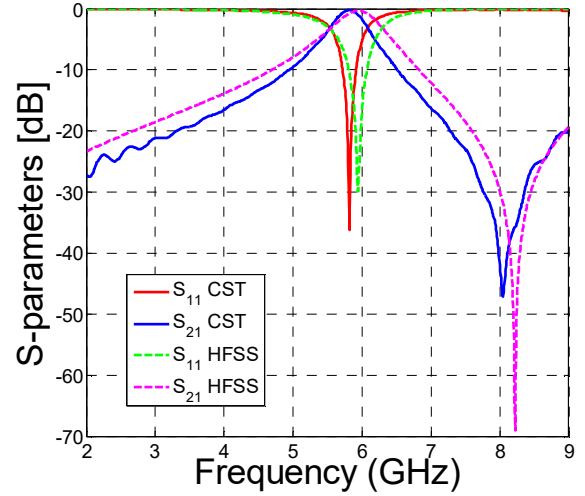

FIGURE 4. Simulated S-parameters of the C-HMC loaded SIW filter.

The main simulation software to obtain the $S$ parameters $\left(S_{11}\right.$ (reflection coefficient) and $\mathrm{S}_{21}$ (transmission coefficient) is CST microwave studio, in the frequency range from $2 \mathrm{GHz}$ to $9 \mathrm{GHz}$. The upcoming discussions are of the results obtained by this software. Additionally, to confirm and validate the results, the same structures are simulated using HFSS software. The results obtained using CST and HFSS are not exactly the same. One can clearly see some differences, and the reason for that is the fact that each one of these simulators applies a different computational technique. By observing the results in fig.4. we can clearly see the excellent narrow band-pass filter with a center frequency of $5.8 \mathrm{GHz}$. Having a recorded input reflection coefficient around $-36 \mathrm{~dB}$, and with insertion loss about $0.05 \mathrm{~dB}$. Furthermore, the rejections bands extend from $2 \mathrm{GHz}$ to 4.9 $\mathrm{GHz}$ and from $6.5 \mathrm{GHz}$ to $9 \mathrm{GHz}$, with attenuation below -10 $\mathrm{dB}$. Additionally, the maximum rejection even reaches -27 $\mathrm{dB}$ at $2 \mathrm{GHz}$ and $-47 \mathrm{~dB}$ at $8 \mathrm{GHz}$.

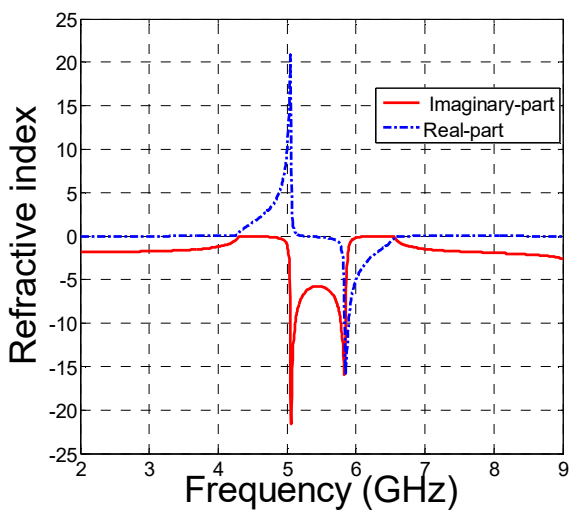

FIGURE 5. SIW engraved with two C-HMC real and imaginary parts of effective refractive index.

Fig. 5, clearly shows that the effective refractive index curves of both the imaginary and the real part have a negative sign around the resonant frequency. 


\section{B. SIW BPF LOADED WITH 4 C-HMC}

In this part, we present a design of a SIW band-pass filter measured in the C-band. We are continuing on using rogers 5880 as a substrate, which has a relative permittivity of 2.2 , and loss tangent 0.0009 , with a thickness of $0.508 \mathrm{~mm}$. The structure is presented in fig.6. Engraving two more C-HMC will further enhance the characteristics of the filter. Meanwhile, In order to better optimize the results, a distance $X$ is chosen, this distance will play the role of inter-resonator that controls the coupling between the C-HMCs, this will extend the width of the filter. The new effective size of this prototype is about $18.36 \mathrm{~mm} \times 14.48 \mathrm{~mm}$.

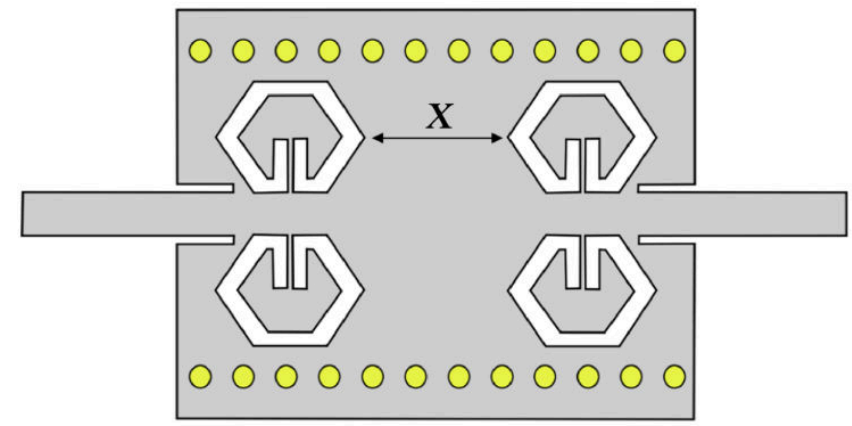

FIGURE 6. The tunable BPF with $04 \mathrm{C}-\mathrm{HMC}$ cells. The value of $\mathrm{X}$ is 5.1 $\mathrm{mm}$

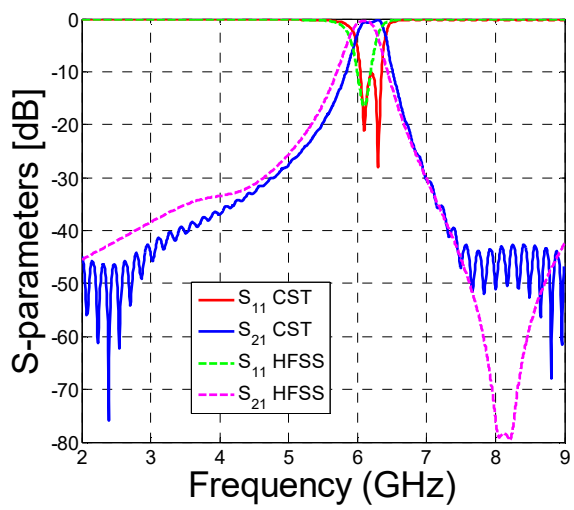

FIGURE 7. Simulation results of the Band-pass filter with $04 \mathrm{C}-\mathrm{HMC}$.

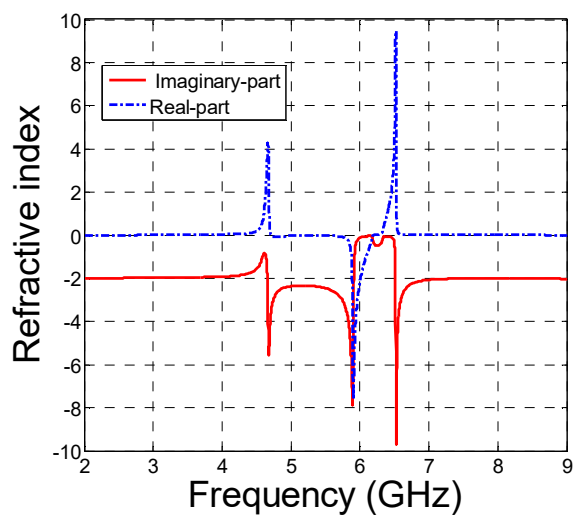

FIGURE 8. the real and imaginary parts of effective refractive index of the four C-HMC BPF.
By observing the results obtained using CST microwave studio, and display in fig.7, it is clear that the bandwidth is wider compared to the first part, where the $S_{11}$ in this case is less than $-10 \mathrm{~dB}$ for the band from $6 \mathrm{GHz}$ to $6.35 \mathrm{GHz}$. But this band is shifted, and that is because of the coupling effect between the C-HMCs, and to the expansion in the filter size. The center frequency is about $6.2 \mathrm{GHz}$ and with an input reflection coefficient level of about $-28 \mathrm{~dB}$. On the other hand, the insertion loss is less than $1 \mathrm{~dB}$. It can also be noted that a good rejection is obtained in the bands: $[2 \mathrm{GHz}$ to 5.8 $\mathrm{GHz}$ ], and [6.5 $\mathrm{GHz}$ to $9 \mathrm{GHz}$ ], with maximum rejection reaching the levels of $-75 \mathrm{~dB}$ and $-68 \mathrm{~dB}$ at the frequencies $2.4 \mathrm{GHz}$ and $8.8 \mathrm{GHz}$, respectively. The results obtained using HFSS (fig.7) show the same behavior with slightly different parameters. On the other hand, the prototype kept the metamaterial properties as shown in fig. 8 .

\section{HMSIW BPF LOADED WITH 2 C-HMC}

The half-mode SIW structure (HMSIW) is able to propagate guided waves in only half the width of the SIW. HMSIW lines are generated by bisecting SIW structures with fictitious magnetic walls since the field dominant mode has a maximum intensity in the middle of the width of the SIW [21].

As seen in fig.9. the SIW is reduced at the lower edge of the micro-band. In other words, the structure is much more miniaturized almost by $50 \%$, while maintaining a very low loss.

In this section, an original HMSIW BPF with two C-HMC is presented in fig.8. by taking off the lower half of the geometry shown in fig.5. while keeping the same dimensions, also sustain the use of rogers 5880 with all of its specifications are kept as before. The effective size of this filter is about: $18.36 \mathrm{~mm} \times 8 \mathrm{~mm}$.

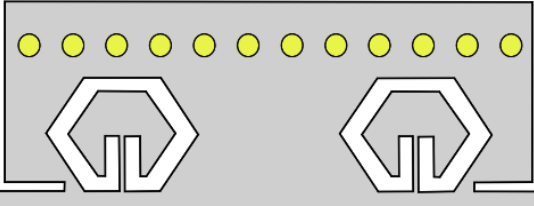

FIGURE 9. Top view of the proposed HMSIW and C-HMC band-pass filter.

The results observed in fig.10. show a band-pass behavior for this filter. The insertion loss is less than $0.4 \mathrm{~dB}$ for the bandwidth from $5.9 \mathrm{GHz}$ to $6.5 \mathrm{GHz}$, with a center frequency of about $6.25 \mathrm{GHz}$ with $-35.7 \mathrm{~dB}$ as an input reflection coefficient. The adaptation is less than $-20 \mathrm{~dB}$ for the frequency range from $6 \mathrm{GHz}$ to $6.44 \mathrm{GHz}$. It is also worth mentioning the excellent rejection under $5.15 \mathrm{GHz}$ and upper 6.9 GHz. The frequencies $2.2 \mathrm{GHz}$ and $7.78 \mathrm{GHz}$ are observed to be with the best rejections of $-34.5 \mathrm{~dB}$ and -69 $\mathrm{dB}$, respectively. Additionally, around the frequency center, the effective refractive index has a negative sign fig. 11. 


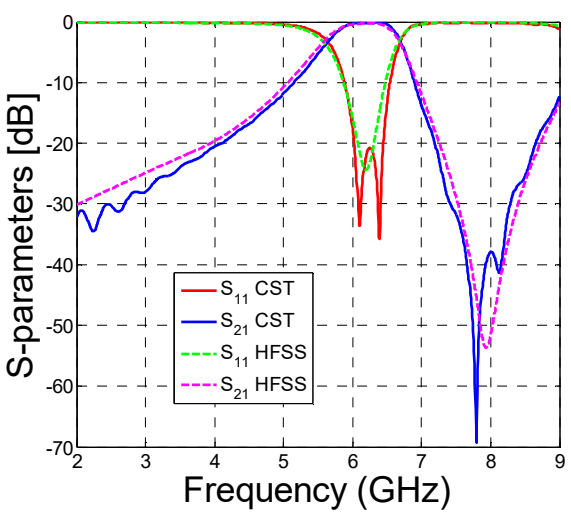

FIGURE 10. HMSIW with C-HMC tunable band-pass filter simulated results.

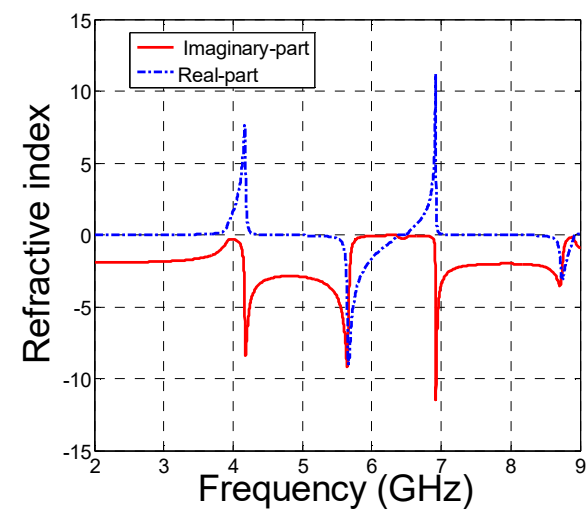

FIGURE 11. The HMSIW effective refractive index.

\section{RECONFIGURABLE SIW BPF LOADED WITH 2 C- HMC}

PIN diode acts as a variable resistor at radio and microwave frequencies, which is mainly controlled by its bias voltage [25]. In a direct polarization, these diodes offer an extremely low impedance, but when it is polarization in the reverse direction the impedance will go higher and with a very low capacity.

The C-HMCs are loaded into the SIW in the same way as the first part (fig.3), Although these resonators have different dimensions this time, so each will operate at a different frequency center. This structure will create a dual-band filter, and to control the reconfigurability, two PIN diodes are implementing in each of the C-HMC gaps as shown in fig. 12.

The parameters in fig. 13 represent the band-pass filter and agility in the center frequency, depending on the presence/ absence of a perfect electrical conductor, determined by the PIN diodes in its ON/OFF states. By activating both D1 and D2 simultaneously, the result is a dual-band filter. Where the diodes behave like a metal bridge connecting the inside of the $\mathrm{C}-\mathrm{HMC}$ with the rest of the conductor.

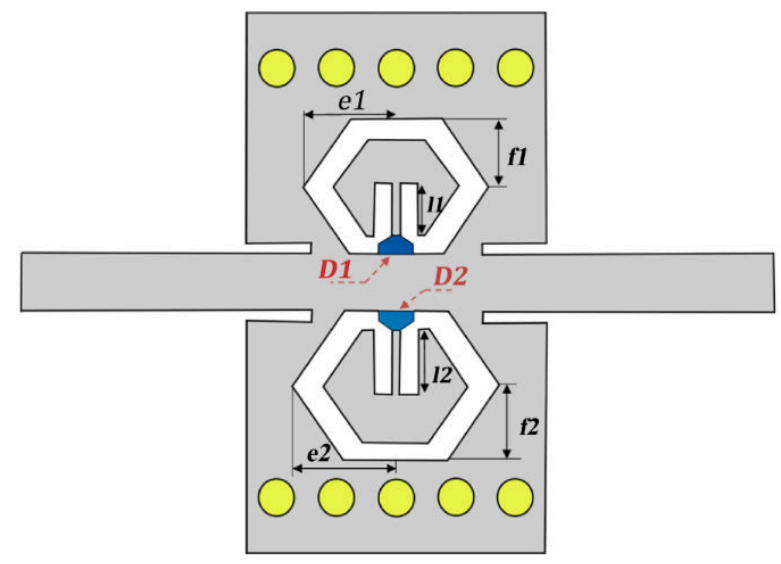

FIGURE 12. Reconfigurable SIW filter loaded with two different sizes CHMCs using two PIN diodes (D1 and D2).

TABLE II. Dimensions of reconfigurable SIW tunable filter with 2 PIN diodes (D1 and D2), (unit: mm).

\begin{tabular}{cc}
\hline \hline Parameters & Quantity \\
\hline$e 1$ & 2.5 \\
$f 1$ & 1.8 \\
$l 1$ & 1.9 \\
$e 2$ & 2.8 \\
$f 2$ & 2 \\
$L 2$ & 2.2 \\
\hline \hline
\end{tabular}

The electrical equivalent circuit presented in fig.13 is for the reconfigurable SIW bandpass filter, which is loaded with two different C-HMC sizes, and two PIN diodes. This circuit can be divided into two parts. The first one is the representation of this filter. Where the inductance $\mathrm{L}_{V}$ indicates the metallic via-holes. The capacitive coupling between the resonators and the waveguide is denoted by $\mathrm{C}_{S}$, at the same time the inductive connection between them is denoted by Ls. this filter design has two different size C-HMCs, each one of them has a representing capacitance and inductance, $\mathrm{Cr} 1$ and $\mathrm{L}_{\mathrm{r} 1}$ for $\mathrm{C}-\mathrm{HMC} 1$ and $\mathrm{C}_{\mathrm{r} 2}$ and $\mathrm{L}_{\mathrm{r} 2}$ for $\mathrm{C}-\mathrm{HMC} 2$. And the mutual coupling between the two resonators is modeled by the capacitance $\mathrm{C}_{\mathrm{C}}$ and the inductance $\mathrm{L}_{\mathrm{C}}$. additionally, both of the resonators $\mathrm{C}-\mathrm{HMC} 1$ and $\mathrm{CHMC} 2$ are connected to the reset of structure with the PIN diodes D1 and D2, which will control the isolation or the connection of either one of the CSRRs individually, or at the same time. 


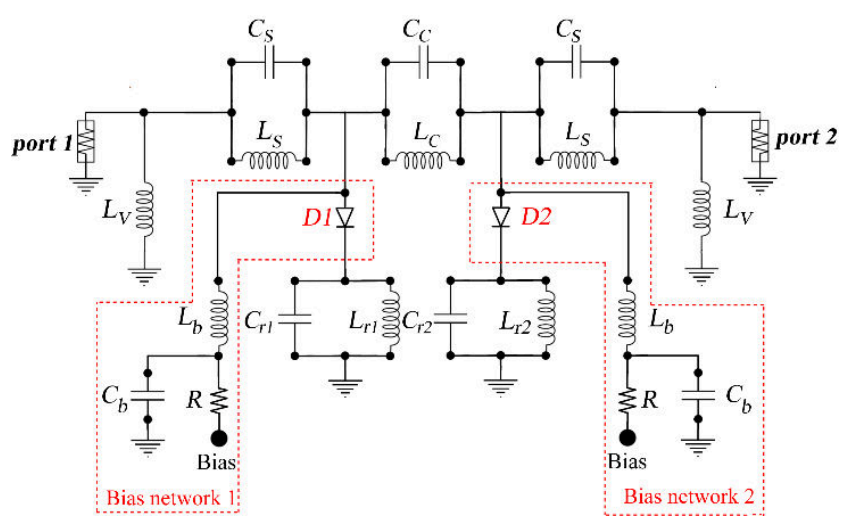

(a)

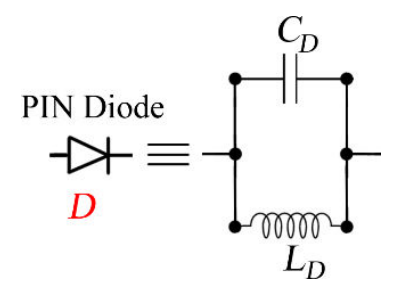

(b)

FIGURE 13. (a): the equivalent circuit of the reconfigurable SIW filter loaded with two different sizes C-HMCs using two PIN diodes, (b) the equivalent circuit of the PIN diode.

The second part of this equivalent circuit is demonstrating the bias feeding network of the diodes. Each of the two diodes has a similar separate bias feeding line because each one is switched independently, thus generating three different filtration cases. $\mathrm{C}_{\mathrm{b}}$ is the DC blocking capacitor that will prevent the DC bias circuit of the PIN diode from being a short-circuit. $\mathrm{L}_{\mathrm{b}}$ models the $\mathrm{RF}$ choke connected with the resentence $\mathrm{R}$ that will limit the current [26]. The values of this bias circuit are chosen to ensure the best possible isolation between the bias network and the bandpass filter. So that the biasing lines will have negligible influence over the operating frequencies.

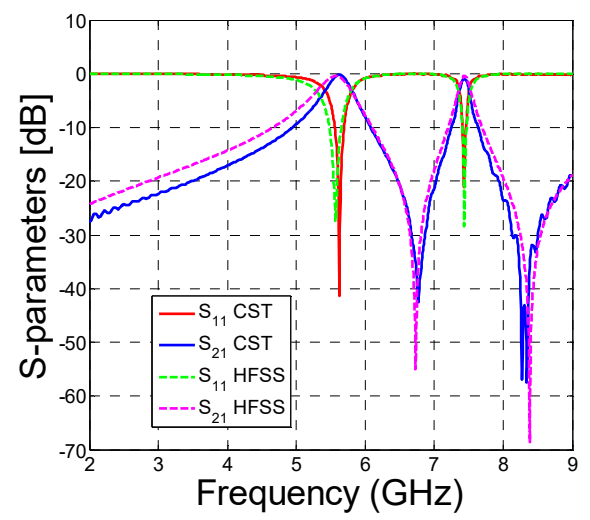

(a)

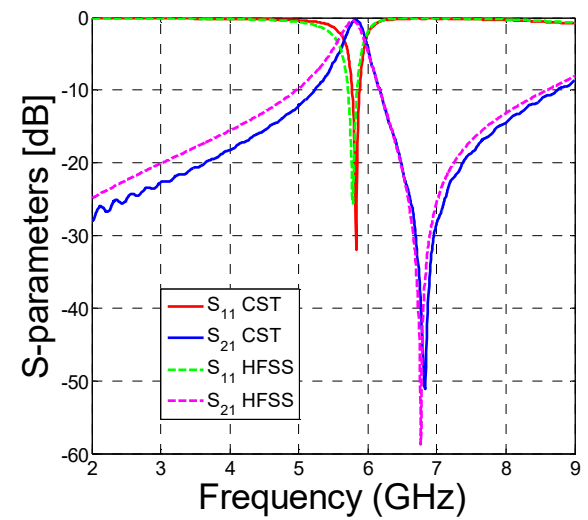

(b)

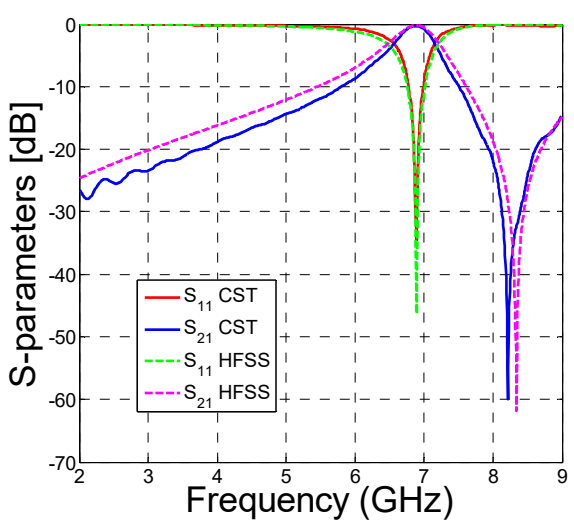

(c)

FIGURE 14. Reconfigurable Simulated S parameters of the proposed filter loaded with the diodes D1 and D2 in its three different cases. (a) D1 ON and D2 ON, (b) D1 OFF, D2 ON, (c) D1 ON and D2 OFF.

The simulated results after the optimizations of the metamaterial filter are represented in fig.14. showing the $S_{11}$ and $\mathrm{S}_{21}$ of the different cases depending on the diodes. A dual-band case is the result of both D1 and D2 in an activated state $(\mathrm{ON})$, where its center frequencies are $5.6 \mathrm{GHz}$ and 7.4 $\mathrm{GHz}$. By turning one of the diodes "OFF" the device will act as a single-bandpass filter. At $5.8 \mathrm{GHz}$ in case of turning D1 $\mathrm{OFF}$, or at $6.8 \mathrm{GHz}$ in case of turning D2 OFF. As we can see the bands are shifted, and this is the effect of the lack of a coupling effect between C-HMCs, due to the absence of one of them, as a result of D1 or D2 being in an OFF state.

All the observed results of the three cases are presented in Table III: 
TABLE III. Details of the parameters of the filter cases depending on the PIN diodes states.

\begin{tabular}{ccccccc}
\hline \hline Cases & D1 & D2 & $\begin{array}{c}\text { Freq } \\
\text { center } \\
(\mathrm{GHz})\end{array}$ & $\begin{array}{c}\text { Insert } \\
\text { loss } \\
(\mathrm{dB})\end{array}$ & $\begin{array}{c}\text { reflection } \\
\text { coefficient } \\
(\mathrm{dB})\end{array}$ & $\begin{array}{c}\text { Filter's } \\
\text { state }\end{array}$ \\
\hline 01 & OFF & ON & 5.8 & $>-0.5$ & -32 & single \\
02 & ON & OFF & 6.8 & $>-0.5$ & -34 & single \\
03 & ON & ON & $5.6 / 7.4$ & $>-0.1$ & $-40 /-20$ & dual
\end{tabular}

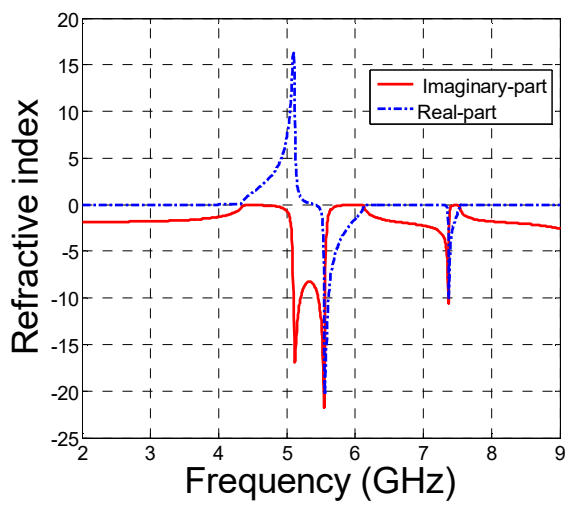

FIGURE 15. The effective refractive index of the reconfigurable filter in case of turning both diodes into $\mathrm{ON}$ states.

The real and imaginary curves of the effective refractive index have a negative sign around both of the resonant frequencies as display in fig. 15. Therefore, this design has kept its metamaterials properties in the dual state (case 03).

TABLE III. Comparison with other reported reconfigurable SIW based tunable band-pass filters.

\begin{tabular}{|c|c|c|c|c|c|}
\hline Refs & $\begin{array}{c}\text { Substrate } \\
\text { relative } \\
\text { dielectric / } \\
\mathrm{h}(\mathrm{mm})\end{array}$ & $\begin{array}{l}\text { tuning } \\
\text { element }\end{array}$ & $\begin{array}{l}\text { the resonant } \\
\text { frequencies } \\
(\mathrm{GHz})\end{array}$ & IL (dB) & $\begin{array}{l}\text { The effective } \\
\text { size }(\mathrm{mm})\end{array}$ \\
\hline$[8]$ & $2.2 / 0.8$ & varicap & $\begin{array}{c}\text { From } 1.5 \text { to } \\
2.9\end{array}$ & $1.4-2$ & $20.3 \times 11$ \\
\hline$[27]$ & $4.6 / 1.6$ & varicap & $\begin{array}{c}\text { From } 1.91 \text { to } \\
2.09\end{array}$ & $1.55-1.87$ & $98.6 \times 92.6$ \\
\hline$[28]$ & $2.2 / 0.7$ & varicap & From 2 to 2.7 & $>2$ & $16 \times 9.8$ \\
\hline [29] & $2.2 / 0.508$ & PIN & $2.3 / 2.6$ & $4.89 / 1.65$ & $30 \times 29$ \\
\hline $\begin{array}{l}\text { This } \\
\text { work }\end{array}$ & $2.2 / 0.508$ & PIN & $\begin{array}{c}5.8 / 6.8 / 5.6- \\
7.4\end{array}$ & $0.5-0.1$ & $8 \times 14.48$ \\
\hline
\end{tabular}

\section{CONCLUSION}

This work introduced in its first part an original SIW bandpass filter and HMSIW BPF, loaded with complementary hexagonal shape metamaterial resonators for C-band applications. The HMSIW BPF has a bandwidth that extends from $5.9 \mathrm{GHz}$ to $6.5 \mathrm{GHz}$, with a $50 \%$ reduction in its size compared to a similar SIW filter. The three proposed filters were analyzed and studied in detail and the results showed very good BPF and metamaterial characteristics. In addition, for the second part, an electronically switchable tunable SIW filter loaded with PIN diode was proposed. The measured results present the possibility to shift the filter frequency center from $5.8 \mathrm{GHz}$ to $6.8 \mathrm{GHz}$ by turning the diodes $\mathrm{ON}$ or OFF. A dual-band case was achieved when both of the diodes are $\mathrm{ON}$, where the center frequencies are $5.6 \mathrm{GHz}$ and $7.4 \mathrm{GHz}$. The main challenges that need to be addressed in future work is how to jump between the single band modes and the dual-band mode with less shifting in the frequency. Along with that, the proposing of new filter structures with more than three cases. Thanks to the very low insertion loss, the small size, and the reconfigurability, there are many applications for these devices, because they function within the c-band. From satellite communications, to some radar systems. Along with some $\mathrm{Wi}-\mathrm{Fi}$, and miniaturized integrated circuit devices, and futuristic technologies.

\section{REFERENCES}

[1] Fgh Q. Y. Xiang, Q. Y. Feng, X. G. Huang, and D. H. Jia, "Electrical tunable microstrip LC bandpass filters with constant bandwidth," IEEE Trans. Microw. Theory Tech, vol. 61, pp. 1124-1130, 2013.

[2] P. W. Wong and I. C. Hunter, "Electronically reconfigurable microwave bandpass filter," IEEE Trans. Microw. Theory Tech, vol. 57, pp. 3070-3079, 2009.

[3] F. $\mathrm{Xu}, \mathrm{K}$. Wu, "Guided-Wave and Leakage Characteristics of Substrate Integrated Waveguide," IEEE Transactions on Microwave Theory and Techniques, 53, 66-73, 2005.

[4] Y. Dong, T. Itoh, "Miniaturized substrate integrated waveguide slot antennas based on negative order resonance," IEEE Transactions on Antennas and Propagation, 58, 3856-3864, 2010.

[5] MA. Rabah, M. Abri, HA. Badaoui, J. Tao, T. H. Vuong, "Compact miniaturized half-mode waveguide/high pass-filter design based on SIW technology screens transmit-IEEE C-band signals," Microwave Opt Technol Lett, 58: 414-418, 2016.

[6] Deslandes D, Wu K. "Substrate integrated waveguide dual-mode filters for broadband wireless systems" [M]. 2003.

[7] Tsai, H.-J., B.-C. Huang, et al., "A reconfigurable bandpass filter based on varactor-perturbed, T-shaped dual-mode resonator," IEEE MWCL, Vol. 24, No. 5, 297-299, 2014.

[8] Jing-Pan Song, Xin-Yi Wang, Feng Wei and Xiao-Wei Shi "Electronically Reconfigurable Varactor-Loaded HMSIW Bandpass Filter" Frequenz; aop, 2017.

[9] Boutejdar, A., "Design of 5 GHz-compact reconfigurable DGS-bandpass filter using varactor-diode device and coupling matrix technique," Microwave and Optical Technology Letters, Vol. 58, No. 2, 2016

[10] B. Belkadi, Z. Mahdjoub, M. L. Seddiki and M. Nedil "A selective frequency reconfigurable bandstop metamaterial filter for WLAN Applications," Turkish Journal of Electrical Engineering \& Computer Sciences, vol. 26, pp 2976-2985, 2018.

[11] Han, Z., K. Kohno, et al., "Tunable terahertz filter and modulator based on electrostatic MEMS reconfigurable 
SRR array," IEEE J. of Selec. Top. in Quan. Electron, Vol. 21, No. 4, 114-122, 2015.

[12] V. Sekar, M. Armendariz, and K. Entesari, "A 1.2-1.6 $\mathrm{GHz}$ substrate-integrated-waveguide RF MEMS tunable filter," IEEE Trans. Microw. Theory Tech, vol. 59, pp. 866-876, 2011.

[13] R. L. Wang, J. F. Wang, et al., "Dual-band suspended stripline filter based on metamaterials," 2017 International Applied Computational Electromagnetics Society Symposium (ACES), IEEE, 1-2, 2017.

[14] Boubakar, H., Abri, M., \& Benaissa, M., "Electronically Switchable SIW Band-Pass Filter Based on S-CSRR Using PIN Diodes for WI-FI Applications," In International Conference in Artificial Intelligence in Renewable Energetic Systems, Springer, Cham. pp. 738746, 2020.

[15] AK. Horestani, Z. Shaterian, J. Naqui, F. Martín, C. Fumeaux, "Reconfigurable and tunable S-shaped splitring resonators and application in band-notched UWB antennas," IEEE T Antenn Propag, 64: 3766-3776, 2016.

[16] Fu S H, Tong C M. "A novel CSRR $\sim$ based defected ground structure with dual'ba ndgap characteristics[J]. Microwave \& Optical Technology Letters," 51(12):2908-2910, 2010.

[17] Dong, Y. D., Yang, T., \& Itoh, T. Substrate integrated waveguide loaded by complementary split-ring resonators and its applications to miniaturized waveguide filters. IEEE Transactions on Microwave Theory and Techniques, 57(9), 2211-2223,2009.

[18] Saktioto, T., R. F. Syahputra, et al., "GHz frequency filtering source using hexagonal metamaterial splitting ring resonators," MOTL, Vol. 59, No. 6, 1337 1340, 2017.

[19] Khelil Fertas, Farid Ghanem, Mouloud Challal, and Rabia Aksas "Design and Development of Compact Reconfigurable Tri-Stopband Bandstop Filter Using Hexagonal Metamaterial Cells for Wireless Applications," Progress In Electromagnetics Research M, Vol. 80, 93-102, 2019.

[20] MA. Rabah, M. Abri, J. Tao, T. Vuong. "Substrate integrated waveguide design using the two-dimensional finite element method," Prog Electromagn Res M, 35:21-30, 2014.

[21] A. Noura, M. Benaissa, M. Abri, H. Badaoui, T. H. Vuong, J. Tao, "Miniaturized half-mode SIW band-pass filter design integrating dumbbell DGS cells," Microw Opt Technol Lett, 1-5, 2019

[22] A. N. Vicente, G. M. Dip and C. Junqueira, "The step by step development of NRW method," in IEEE International Microwave Conference. (IMOC), pp. 738742,2011

[23] W. B. Weir, "Automatic measurement of complex dielectric constant and permeability at microwave frequencies," in Proc. of the IEEE, vol. 62, pp. 33-36, 1974.

[24] D. R. Smith, S. Schultz, P. Markoš and C. M. Soukoulis, "Determination of effective permittivity and permeability of metamaterials from reflection and transmission coefficients," in phys Rev B, vol. 65, pp. 195104, 2002

[25] Garver RV. Microwave Diode Control Devices. Artech House, 1977.

[26] M. Watertown, "The pin diode circuit designers' handbook," Microsemi corporation, Santa-Ana: California, Jul. 1992.

[27] Sam WY, Zakaria Zahriladhabin. "Design of reconfigurable integrated substrate integrated waveguide (SIW) filter and antenna using multilayer approach," Int J RF Microw Comput Aided Eng, e21561, 2018.

[28] H. Yue, X. Zhang, F. Wei, J. Song, X. Shi "A Half Mode Substrate Integrated Waveguide Reconfigurable Bandpass Filter Based on S CSRR,"10.1109/ICMMT, 8563751,1-3, 2018.

[29] Q.-Y. Xiang, Q.-Y. Feng, X.-G. Huang \& D.-H. Jia "Substrate integrated waveguide filters and mechanical/ electrical reconfigurable half-mode substrate integrated waveguide filters," Journal of Electromagnetic Waves and Applications, 26:13, 1756-1766, 2012.

[30] WwW.cst.com CST Microwave studio, Computer Simulation Technologyc, Framingham, MA.

[31] High Frequency Structure Simulator (HFSS v13), Ansoft Corp. 